\title{
Structural Optimization of Steel Cantilever Used in Concrete Box Girder Bridge Widening
}

\author{
Qian Wang, ${ }^{1}$ Wen-liang Qiu, ${ }^{1}$ and Sheng-li $X \mathbf{u}^{2}$ \\ ${ }^{1}$ Faculty of Infrastructure Engineering, Bridge Science Research Institute, Dalian University of Technology, Dalian, \\ Liaoning 116024, China \\ ${ }^{2}$ School of Energy and Power Engineering, Dalian University of Technology, Dalian, Liaoning 116024, China
}

Correspondence should be addressed to Sheng-li Xu; xusl@dlut.edu.cn

Received 3 April 2015; Revised 11 June 2015; Accepted 21 June 2015

Academic Editor: Zdeněk Kala

Copyright (c) 2015 Qian Wang et al. This is an open access article distributed under the Creative Commons Attribution License, which permits unrestricted use, distribution, and reproduction in any medium, provided the original work is properly cited.

\begin{abstract}
The structural optimization method of steel cantilever used in concrete box girder bridge widening is illustrated in this paper. The structural optimization method of steel cantilever incorporates the conceptual layout design of steel cantilever beam based on the topological theory and the determination of the optimal location of the transverse external prestressed tendons which connect the steel cantilever and the box girder. The optimal design theory and the analysis process are illustrated. The mechanical model for the prestressed steel cantilever is built and the analytical expression of the optimal position of the transverse external tendon is deduced. At last the effectiveness of this method is demonstrated by the design of steel cantilevers which are used to widen an existing bridge.
\end{abstract}

\section{Introduction}

Structural optimization is an important tool for structural designers because it allows the designers to tailor a structure to a specific performance level required by the owner. Structural optimization is nowadays common in mechanical and aeronautical engineering, and in recent years, it has been progressively adopted for structural engineering and bridges [1-10]; particularly in the aspects of generation of strut-and-tie patterns for reinforced concrete structures [1113] and fiber-reinforcement retrofitting structures [14-16], the topology optimization is widely used. Aiming at different structures the corresponding optimization schemes should be proposed to help the designers to find structural forms that not only better exploit material but also give the structure greater aesthetic value.

In this paper, the structural optimization method of steel cantilever which is used in concrete box girder bridge widening is illustrated. Steel cantilever widening concrete box girder method is a new box girder widening method without piers, which has many advantages, such as shorter construction period, open clearance of span, lesser traffic interference, better traffic capacity, and better economic benefit [17, 18]. According to this method, the original bridge deck is widened by the orthotropic steel decks that are laid on the cantilevers (Figure 1). The cantilevers are connected to the original box girder by transverse external prestressed tendons. Pairs of steel cantilever beams are installed on both sides of the original box girder at regular distance ( $L$, see Figure 2$)$. As it is shown in Figure 3, postpouring concrete diaphragms are used to connect with the newly added steel cantilever beams. Concrete postpouring diaphragms are placed in pairs and their quantities and locations should be consistent with those of newly added steel cantilever beams.

The widened box girder is a special structure of steel and concrete combined transversely. Ensuring the reasonable stress on interface between the steel cantilever and the box girder is an important precondition to guarantee that the entire structures work together. Besides, the beautiful shape and reasonable function holes which are used to settle pipelines are essential to the steel cantilevers. The reasonable design of the steel cantilevers is the key problem. Although the conceptual design of the steel cantilevers depends on the designer's intuition and ability to recognize the role of steel 


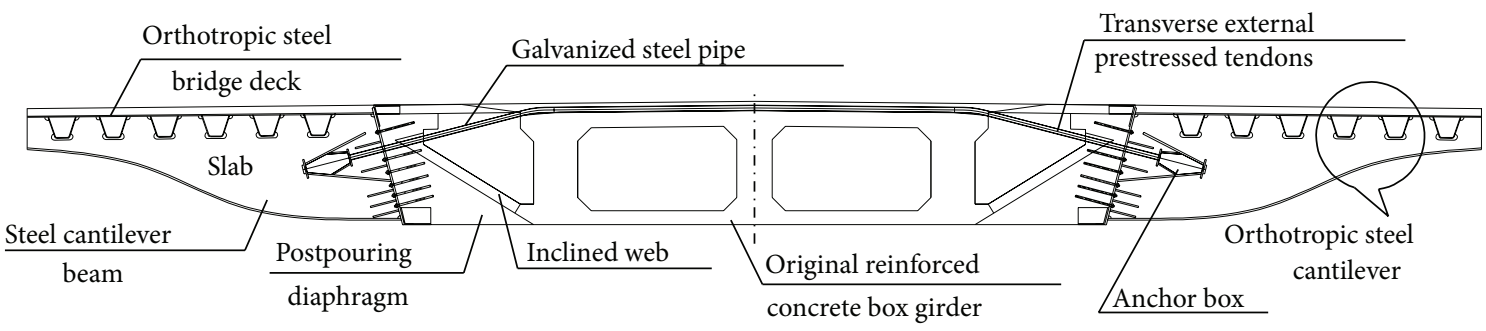

FIGURE 1: Sectional drawing of original box girder widened by steel cantilevers.

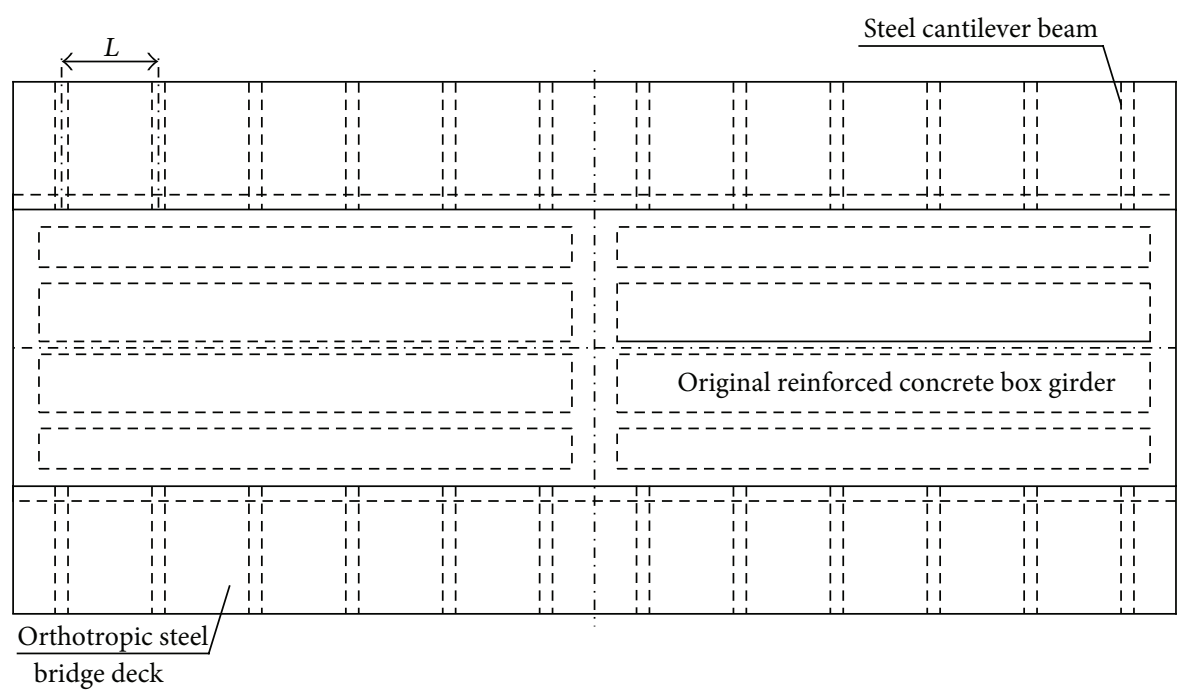

FIGURE 2: Plane figure of original box girder widened by steel cantilevers.

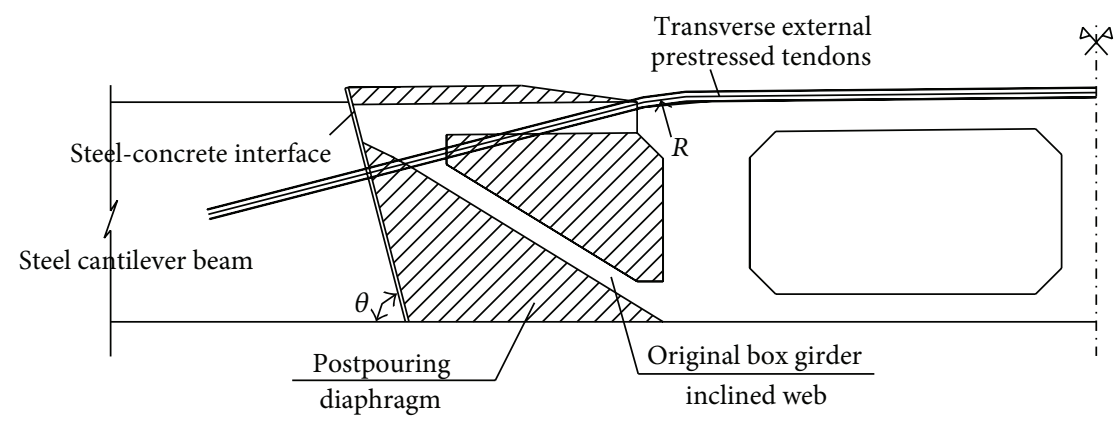

FIgURE 3: Diagram of interface between steel and concrete.

cantilevers in transferring weight and loads to the original box girder, currently, structural optimization may help the designer find the most suitable shape and layout of a steel cantilever from a structural and an architectural point of view $[19,20]$.

The topic of this paper is a structural optimization problem which incorporates the conceptual layout design of the steel cantilever and the determination of the optimal location of the transverse external prestressed tendons. The author applied the topological optimization theory to the shape and layout design of steel cantilever and builds the mechanical model for the prestressed steel cantilever. Then the analytical expression of the reasonable acting position of the transverse external prestressed tendons on the steel cantilever is deduced and the steel cantilever structural optimization scheme is proposed.

\section{The Optimization Problem Statement}

There are two key issues for optimization design of the steel cantilever.

The first one is the conceptual layout design of steel cantilever beam. The steel cantilever is newly added to the original box girder; the additional live load and dead load on the steel cantilever should be effectively transmitted to the original box girder. This requires the shape, layout of steel 
cantilever, and the setting of function holes for the pipelines should not damage the structure stiffness; namely, the load path of steel cantilever should not be broken.

The second issue is the decision of the optimal location of the transverse prestressed tendons. The transverse external prestressed tendons which connected the original box girder and the steel cantilevers are key components of the widened structure, whose location influences the stress on the steelconcrete interface as shown in Figure 3 directly. In order to ensure that the steel cantilever is connected with original concrete box girder closely and the concrete at interface is not crushed, the optimal location of transverse prestressed tendons is an important prerequisite. The reasonable stress state of steel-concrete interface is that there should be no tensile stress on the key position of interface and the compressive stress should not exceed the compressive strength of the concrete at interface, which should be obeyed in deducing the optimal location of the prestressed tendons.

\section{Topological Optimization of the Steel Cantilever}

The aim of topological optimization is to find a conceptual layout of steel cantilever by distributing a given amount of material in a domain, thereby achieving the lightest and stiffest structure while satisfying certain specified design constraints.

Many innovative optimization methods and algorithms have been developed and reported [21-29]. In this paper, topological optimization was carried out through the SIMP method [30-33], due to its computational efficiency and conceptual simplicity.

3.1. Numerical Model. Steel-concrete interface is the key position for this composite structure. While pursuing optimization design of the entire steel cantilever beam to make it light, convenient to be processed, and well-formed, it should be premised on that the vehicle load and dead load on steel cantilevers could be transmitted to the interface effectively. The dead load here is the weight of orthotropic steel bridge deck and the bridge deck pavement including concrete paving layer and asphalt concrete paving layer.

In order to get the optimal transmitting path of load on the steel cantilever from which to the interface, the interface of steel cantilever is considered as consolidated from the perspective of model simplification. Because the orthotropic bridge deck slab should be set at top of steel cantilever actually, U-shaped slots need to be reserved for placing bridge deck slab, as it is shown in Figure 4. Thus, singleended consolidated structure with U-shaped slots is the basic structure for topological optimization of steel cantilever.

The load on steel cantilever involves dead load and motor vehicle wheel load. The uniform force " $q_{0}$ " of dead load as shown in Figure 5 is the weight of orthotropic bridge deck and deck pavement equally distributed on each steel cantilever. According to the regulations of General Code for Design of Highway Bridges and Culverts [34], the most unfavorable wheel load distribution is arranged. Setting widening one lane

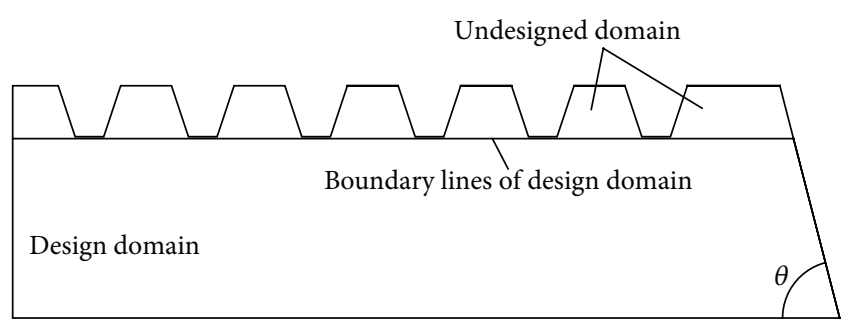

FIGURE 4: Actual structure for topological optimization.

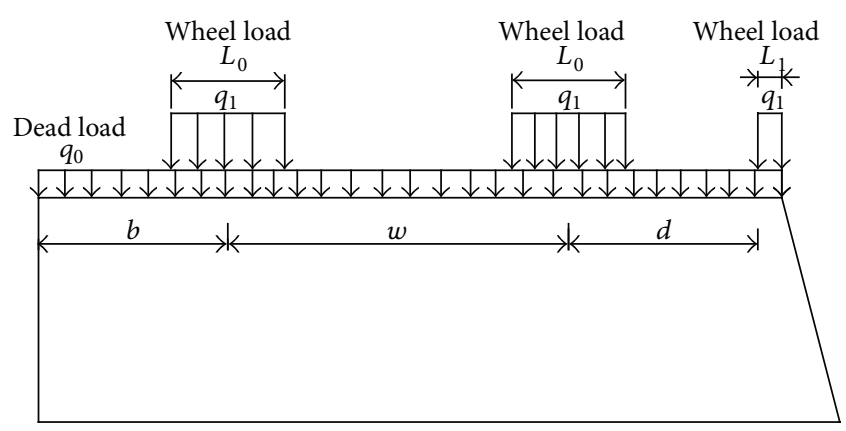

FIgURE 5: Topological optimization structural under Load Case 1.

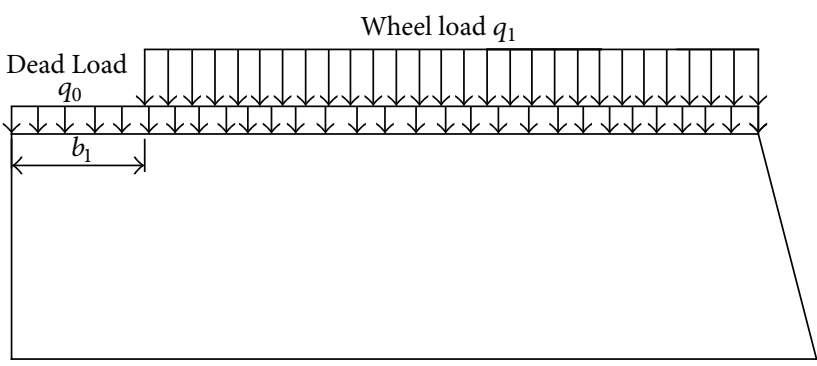

Figure 6: Topological optimization structure under Load Case 2.

unilaterally as an example, within widening range of steel cantilever, two wheels and part of one wheel may be arranged. Wheel uniform load " $q_{1}$ " could be calculated according to the vehicle axle load and wheel action range. Optimization analysis for Load Case I refers to the combined action of dead load uniform force " $q_{0}$ " and actual most unfavorable wheel load, as it is shown in Figure 5.

The position of wheel load is random and not fixed within the range of the motor vehicle possible passing. Thus, besides the above most unfavorable loading case, wheel load also has other various loading cases. In order to make optimization results widely suitable for various loading conditions, wheel load is hereby fully distributed within the range that wheel load may appear conservatively, which is Load Case 2 as shown in Figure 6. Besides the dead load and wheel load on the steel cantilever, the self-weight of the steel cantilever also should be considered during the topological optimization process.

3.2. Mathematical Model. In this paper, minimum compliance of the system is regarded as objective function of 
the structure optimization. In similar design area, when boundary conditions and load are certain, the smaller the compliance is, the larger the stiffness is $[33,35]$.

Suppose external force exerted on the system as $F$, then its strain energy could be expressed as

$$
E_{s}=\frac{1}{2} \int_{\Omega} \varepsilon(u)^{T} D \varepsilon(u) d \Omega=\frac{1}{2} F^{T} U .
$$

In the equation, $\Omega$ is given design area; $\varepsilon(u)$ is strain under load $F ; u$ is elastic deformation of any point in design area under load $F ; D$ is elastic matrix; $F$ is load vector; and $U$ is displacement vector.

Equilibrium equation of the system is expressed as

$$
K U=F,
$$

wherein $K$ represents the stiffness matrix of the system and $K^{T}=K$. Joining (1) and (2) together, it could be concluded that

$$
E_{s}=\frac{1}{2} U^{T} K^{T} U=\frac{1}{2} U^{T} K U .
$$

Compliance of the system could be expressed as $C=F^{T} U$. Compared with (1), it could be concluded that if compliance of the system is minimum, its strain energy is minimum.

Mathematical model for topological optimization of steel cantilever structure is established as

$$
\begin{aligned}
& \rho(x)=x_{i} \rho_{0}, \\
& E(x)=x_{i}{ }^{P} E_{0} ;
\end{aligned}
$$

wherein $\rho_{0}$ and $E_{0}$ represent density and elastic matrix of cantilever after subdivision, respectively; $x_{i}$ represents relative density of the element; and $P$ represents penalty factor.

As it is illustrated in Section 3.1, actual topological structure is mainly designed according to two load cases (see Figures 5 and 6). Making stiffness of steel cantilever the largest, the best material distribution results can be calculated. In order to ensure that the steel cantilever can transmit the loads to the interface effectively, Load Case 1 and Load Case 2 are considered together to confirm the boundary and layout of steel cantilever. The multiload approach [36, 37], which considers multiload cases by using the weight coefficient, can be used to perform the optimization boundary and layout of steel cantilever.

Considering two load cases, the topology optimization problem to minimize the compliance of the steel cantilever structure while it is subjected to a limited amount of material in the design domain can be written as

$$
\begin{array}{cl}
\text { Find } & X=\left[x_{1}, x_{2}, x_{3}, \ldots, x_{n}\right]^{T} \\
\text { Minimize: } & C(X)=c_{1} U_{1}^{T} K U_{1}+c_{2} U_{2}^{T} K U_{2} \\
= & c_{1} \sum_{i=1}^{n}\left(x_{i}\right)^{P} U_{1 e}^{T} K U_{1 e} \\
& +c_{2} \sum_{i=1}^{n}\left(x_{i}\right)^{P} U_{2 e}^{T} K U_{2 e}
\end{array}
$$

$$
\begin{array}{ll}
\text { Subjected to: } & \sum_{i=1}^{n} x_{i} \leq f \\
& K U_{1}=F_{1} \\
& K U_{2}=F_{2} \\
& 0<x_{\text {min }}<x_{i}<1 .
\end{array}
$$

In the equation, relative density of the element $x_{i}$ is design variable; $f$ represents volume coefficient; $K U_{1}=F_{1}$ is the equilibrium equation for Load Case 1 , and $K U_{2}=F_{2}$ is the equilibrium equation for Load Case $2 ; c_{1}$ and $c_{2}$ are the weight coefficients for Load Case 1 and Load Case 2. In this case, the mathematical model could be described as finding density distribution of each element to make the stiffness of the steel cantilever the largest in certain combination of load weight coefficients.

In this paper, the optimization analysis is performed using the topological optimization module in ANSYS.

In design domain of steel cantilever, function holes which are used to settle pipelines should be placed in the area that does not need to arrange materials. Leading the obtained optimization results into cartographic software, the shape and function holes of the steel cantilever that do not damage the structure stiffness could be designed according to material distribution results, which means the shape and layout of the function holes design are designed on the premise of ensuring not to damage load transmission path and maintaining the structure stiffness. The specific design procedure will be described later in the application of an actual bridge example.

\section{Determination of Optimal Location of the Transverse External Tendon}

4.1. Mechanical Model. While analyzing the stress on the interface between steel cantilever and concrete postpouring diaphragm, we suppose that there is no elastic deformation caused to steel cantilever, but only rigid body moves and rotates. The counterforce on concrete interface is in straightline distribution, as it is shown in Figures 7 and 8.

The key issue for ensuring that the special composite structures work cooperatively refers to the fact that newly added steel cantilever should contact with concrete box girder closely and the concrete at interface will not be crushed, which means tensile stress will not happen to the interface and compressive stress should not exceed the compressive strength of the concrete at interface.

Combined with actual project, from construction stage to application stage, the stress at steel-concrete interface involves two critical cases. Critical Case I is in construction stage. When steel cantilever is well installed, transverse prestressed tendons are stretched, while orthotropic bridge deck slab and bridge deck pavement are not constructed. During this period, the prestress load takes the main role. The compressive stress on top edge of steel-concrete interface is maximum and the stress on bottom edge of interface is minimum. Critical Case II is in the application stage. In 


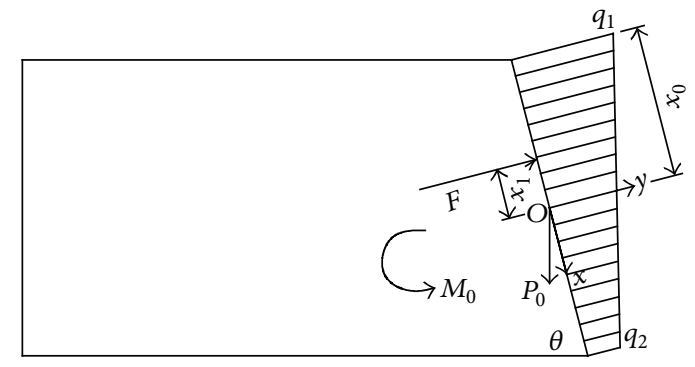

FIGURE 7: Mechanical model one of steel-concrete interface.

this stage, the orthotropic bridge deck slab is installed and bridge deck pavement is ready. When wheel load is located at the most unfavorable loading position (see Figure 5), the stress on top edge of steel-concrete interface is minimum and the stress on bottom edge of interface is maximum. Under the above two critical cases, if tensile stress is ensured not to happen to top edge and bottom edge of interface and compressive stress is ensured not to exceed compressive strength of the concrete at interface, the stress distribution under other general load cases can be determined to satisfy the structural requirements.

\subsection{Theoretical Inference for the Optimal Position of the Transverse External Tendon}

4.2.1. Stress Analysis on Critical Case I. Under this case, only the self-weight of steel cantilever and the action of external prestressed tendon are considered. Suppose that any point " $O$ " on the steel cantilever interface is reference point for the force analysis and the equivalent stress analysis is performed based on which. Meanwhile, simplify self-weight of steel cantilever beam as " $P_{0}$ " concentrated force and " $M_{0}$ " bending moment that go through the reference center "O." Transverse external prestress is " $F$ " and the distance between its load position and bending center is " $x_{1}$." Length of interface is " $l$," the distance between top edge of interface and bending center is " $x_{0}$," and the distance between bottom edge of interface and bending center is " $l-x_{0}$." Counterforce on the top edge of interface is " $q_{1}$ " and counterforce on the bottom edge of interface is " $q_{2}$." As elasticity modulus of steel is much larger than that of concrete, the stress on the interface is supposed to be in linear distribution. Mechanical model for Critical Case I should be referred to in Figure 7.

In Figure 7, it could be concluded that

$$
\begin{aligned}
F-P_{0} \cos \theta & =\int_{-x_{0}}^{l-x_{0}} q(x) d x \\
F x_{1}+\int_{-x_{0}}^{l-x_{0}} q(x) \cdot x d x-M_{0} & =0 .
\end{aligned}
$$

From (6), $q_{1}$ and $q_{2}$ can be expressed as

$$
\begin{aligned}
& q_{1}=\frac{2\left(F-P_{0} \cos \theta\right)}{l}-q_{2} \\
& q_{2}=\frac{2\left(F-P_{0} \cos \theta\right)}{l}-q_{1} .
\end{aligned}
$$

In order to ensure good collaboration of the steel cantilever and original box girder, it should meet the requirements that the tensile stress will not happen to bottom edge of interface and compressive stress at top edge will not exceed compressive strength $[\sigma]$ of the concrete at interface. Thus, it needs to meet $q_{1} \leq[\sigma] t$, where " $t$ " represents the width of the concrete postpouring diaphragm, and it also needs to meet $q_{2} \geq 0$.

With the above safety requirements, (8) can be changed as

$$
\begin{aligned}
& q_{1} \leq \frac{2\left(F-P_{0} \cos \theta\right)}{l} \\
& q_{2} \geq \frac{2\left(F-P_{0} \cos \theta\right)}{l}-[\sigma] \cdot t .
\end{aligned}
$$

From $q_{1} \leq[\sigma] \cdot t$ and $q_{1} \leq 2\left(F-P_{0} \cos \theta\right) / l$, the following equation is gotten:

$$
q_{1} \leq a_{0}
$$

wherein $a_{0}=\min \left\{[\sigma] \cdot t, 2\left(F-P_{0} \cos \theta\right) / l\right\}$.

From $q_{2} \geq 0$ and $q_{2} \geq 2\left(F-P_{0} \cos \theta\right) / l-[\sigma] \cdot t$, the following equation is gotten:

$$
q_{2} \geq b_{0}
$$

wherein $b_{0}=\max \left\{0,2\left(F-P_{0} \cos \theta\right) / l-[\sigma] \cdot t\right\}$.

Then, from (7), taking $x_{0}=l / 2$, it could be concluded that

$$
F x_{1}-\frac{1}{2}\left(q_{1}-q_{2}\right) \cdot l \cdot\left(\frac{2 l}{3}-\frac{l}{2}\right)-M_{0}=0 .
$$

Joining (8) into (12), we can get

$$
\begin{aligned}
& F x_{1}-\frac{l^{2}}{6}\left[\frac{\left(F-P_{0} \cos \theta\right)}{l}-q_{2}\right]=M_{0} \\
& F x_{1}-\frac{l^{2}}{6}\left[q_{1}-\frac{\left(F-P_{0} \cos \theta\right)}{l}\right]=M_{0} .
\end{aligned}
$$

From (10) and (13), the following equation can be gotten:

$$
x_{1} \leq\left[\frac{a_{0} l^{2}-\left(F-P_{0} \cos \theta\right) l}{6}+M_{0}\right] \cdot \frac{1}{F} \text {. }
$$

From (11) and (14), the following equation can be gotten:

$$
x_{1} \leq\left[\frac{\left(F-P_{0} \cos \theta\right) l-b_{0} l^{2}}{6}+M_{0}\right] \cdot \frac{1}{F} \text {. }
$$

Joining (15) and (16) together, the upper limit of $x_{1}$ is given by

$$
\begin{aligned}
x_{1} & \leq \min \left\{\left[\frac{a_{0} l^{2}-\left(F-P_{0} \cos \theta\right) l}{6}+M_{0}\right]\right. \\
& \left.\cdot \frac{1}{F},\left[\frac{\left(F-P_{0} \cos \theta\right) l-b_{0} l^{2}}{6}+M_{0}\right] \cdot \frac{1}{F}\right\},
\end{aligned}
$$




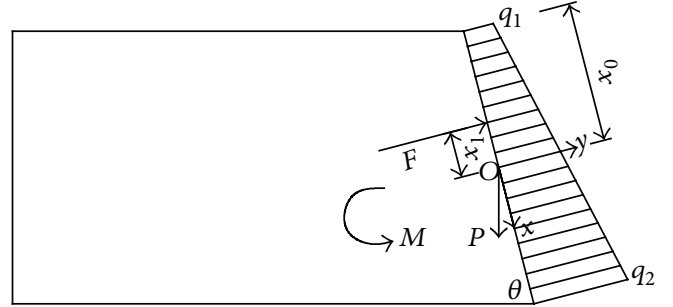

Figure 8: Mechanical model two of steel-concrete interface.

4.2.2. Stress Analysis on Critical Case II. Simplify the dead load on steel cantilever and wheel load as " $P$ " concentrated force and " $M$ " bending moment that go through the reference point "O." The transverse external prestress is " $F$ " and the distance between its load position and bending center is " $x_{1}$." Length of the interface is " $l$," the distance between top edge of cross section and bending center is " $x_{0}$," and the distance between bottom edge of interface and bending center is " $l-x_{0}$." Counterforce on top edge of interface is " $q_{1}$ " and counterforce on bottom edge of interface is " $q_{2}$." The stress on the interface is also supposed to be in linear distribution. Mechanical model for Critical Case II is shown in Figure 8.

From Figure 8, it could be concluded that

$$
\begin{aligned}
F-P \cos \theta & =\int_{-x_{0}}^{l-x_{0}} q(x) d x \\
F x_{1}+\int_{-x_{0}}^{l-x_{0}} q(x) \cdot x d x-M & =0 .
\end{aligned}
$$

From equilibrium of friction along $x$-axis, it can be gotten that

$$
P \cdot \sin \theta<\mu \cdot \int_{-x_{0}}^{l-x_{0}} q(x) \cdot d x
$$

From (18) and (20), the lower limit of external prestress " $F$ " could be valued as

$$
F>P \cdot\left(\frac{\sin \theta}{\mu}+\cos \theta\right) .
$$

In order to ensure good collaboration of steel cantilever and original box girder in Critical Case II, it should meet the requirements that tensile stress will not happen to top edge of interface and compressive stress on the bottom edge of interface will not exceed compressive strength of the concrete at interface. Thus, it needs to meet $q_{1} \geq 0$ and $q_{2} \leq[\sigma] t$ at the same time.

Referring to the derivation process of Critical Case I, lower limit of " $x_{1}$ " could be expressed as

$$
\begin{gathered}
x_{1} \geq \max \left\{\left[M-\frac{(F-P \cos \theta) l-a l^{2}}{6}\right]\right. \\
\left.\cdot \frac{1}{F},\left[M-\frac{b l^{2}-(F-P \cos \theta) l}{6}\right] \cdot \frac{1}{F}\right\} .
\end{gathered}
$$

4.2.3. Load Position of Transverse Prestress and Value of External Prestress. Combining (17) and (22), theoretical value range of " $x_{1}$ " and the load position of transverse prestressed tendon could be expressed as

$$
\begin{aligned}
& x_{1} \geq \max \left\{\begin{array}{l}
{\left[M-\frac{(F-P \cos \theta) l-a l^{2}}{6}\right] \cdot \frac{1}{F}} \\
{\left[M-\frac{b l^{2}-(F-P \cos \theta) l}{6}\right] \cdot \frac{1}{F}}
\end{array}\right\} \\
& x_{1} \leq \min \left\{\begin{array}{l}
{\left[\frac{a_{0} l^{2}-\left(F-P_{0} \cos \theta\right) l}{6}+M_{0}\right] \cdot \frac{1}{F}} \\
{\left[\frac{\left(F-P_{0} \cos \theta\right) l-b_{0} l^{2}}{6}+M_{0}\right] \cdot \frac{1}{F}}
\end{array}\right\} .
\end{aligned}
$$

Reasonable values of " $F$ " and " $x_{1}$ " are the important premise to ensure the stress on the interface satisfy the requirements. To sum up, in the steel cantilever widening method, when making design for transverse external prestressed tendon, (21) should be referred to, according to which, limit for transverse external prestress " $F$ " is provided. Within this range, type and number of prestressed tendons could be set to confirm the value of " $F$." Then, from (23), value range of " $x_{1}$ " could be calculated, namely, theoretical range for load position of transverse external prestress tendon. The value of " $F$ " can be adjusted until the load position of transverse prestressed tendon is reasonable and practical.

\section{Structural Optimization Scheme of Steel Cantilever}

Integrating the topological optimization design for the boundary and layout of steel cantilever and the theoretical derivation result for optimal position of transverse prestressed tendon, the structural optimization scheme of steel cantilever used in concrete box girder widening is proposed. First, make topological optimization analysis on the setting area and design the boundary and layout of steel cantilever beam. Second, based on the optimized shape and combining two critical cases, value range of transverse external prestress and reasonable action range of transverse prestressed tendon could be deduced. Third, select proper value of " $F$ " to ensure that position of transverse external prestressed tendons is reasonable and practical and then make detail design on stiffening rib near interface of steel cantilever beam. Finally, make accurate finite element analysis on contact stress at steelconcrete interface under critical case to verify if the values of design parameters are reasonable. Steel cantilever could be designed according to this optimization analysis scheme, which could effectively reduce trials and save computing resources.

\section{Application}

6.1. Actual Bridge Example. In Figure 9, it shows the section of a two-lane bridge. This bridge is a reinforced concrete continuous box girder bridge having a width of $9.5 \mathrm{~m}$. The 


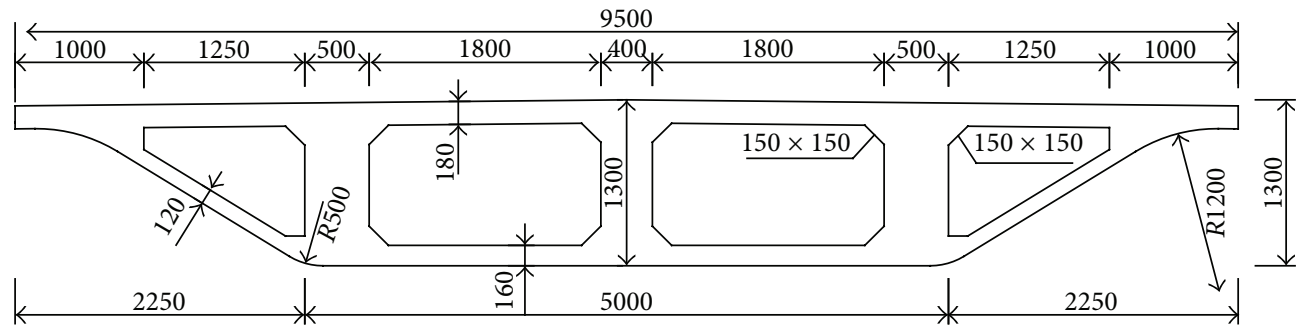

FIGURE 9: Standard cross section of Dalian northeast road overpass (unit: $\mathrm{mm}$ ).

beam depth is $1.3 \mathrm{~m}$; the thicknesses of roof and bottom plate are $18 \mathrm{~cm}$ and $16 \mathrm{~cm}$, respectively. And the thicknesses of webs are shown in Figure 9. The results of health survey indicate that the bridge is in good condition. In order to ease traffic pressure of this bridge, it needs to be widened from two lanes to four lanes. This bridge is of an important geographical location with intensive underground pipelines and surrounding buildings and the traffic is not allowed to be stopped. In order to reduce building demolition and prevent traffic confliction on the ground, the steel cantilever widening concrete box girder method without piers is adopted to widen the bridge.

6.2. Optimization Design for the Shape of Steel Cantilever. As it is illustrated in Section 3.1, fully distributed dead load and uniform wheel load are the major load case to control the shape design of steel cantilever. For this bridge, pavement layer of pitch is $8 \mathrm{~cm}$ and pavement layer of concrete is $10 \mathrm{~cm}$. Thickness of the roof of orthotropic bridge deck slab is $14 \mathrm{~mm}$ and thickness of U-shaped rib is $6 \mathrm{~mm}$. A pair of steel cantilever beams are set every $3 \mathrm{~m}$, thickness of the web is $14 \mathrm{~mm}$, and thickness of bottom plate is $20 \mathrm{~mm}$. Combined with the above actual loading conditions, dead uniform load " $q_{0}$ " and wheel uniform load " $q_{1}$ " are calculated as $q_{0}=$ $21.9 \mathrm{kN} / \mathrm{m}$ and $q_{1}=140.8 \mathrm{kN} / \mathrm{m}$ (axle weight of vehicle is $130 \mathrm{kN}$ which considers dynamic load magnification factor as $1.3)$, respectively. Load arrangement form is the same as in the above Figures 5 and 6.

The inclination angle of interface " $\theta$ " should be determined by comprehensively considering the following factors: transverse external prestressed tendons should be vertical to the interface; the external prestressed tendons which cross the original box girder should try to minimize the damage of the original structure; bending radius " $R$ " of transverse external prestressed tendons should meet the minimum specified value which is $1.5 \mathrm{~m}$ for epoxy coated strands. With integration of the above factors, the inclination angle of interface here is valued as $\theta=75.5^{\circ}$ and the bending radius of transverse prestressed tendons is $R=2 \mathrm{~m}$.

As referred to in Section 3.2, the objective function of the topological optimization problem is to make the stiffness of the steel cantilever the largest. Design variable is the relative density of the element for the materials within design area. In order to ensure that the steel cantilever transmits the loads to the interface effectively, Load Case 1 and Load Case 2 are considered together to confirm the boundary and layout

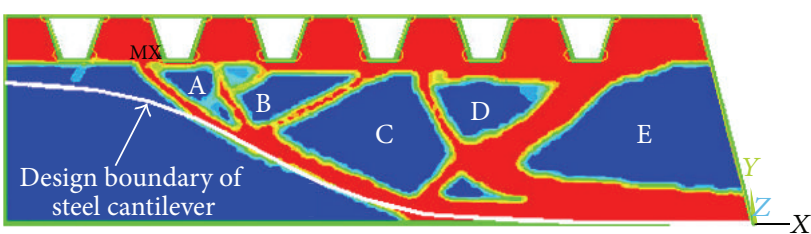

Figure 10: Topological optimization result for load weight coefficient $(1,0)$.

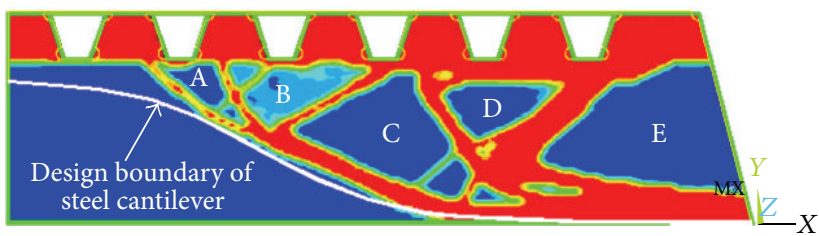

FIGURE 11: Topological optimization result for load weight coefficient $(0.5,0.5)$.

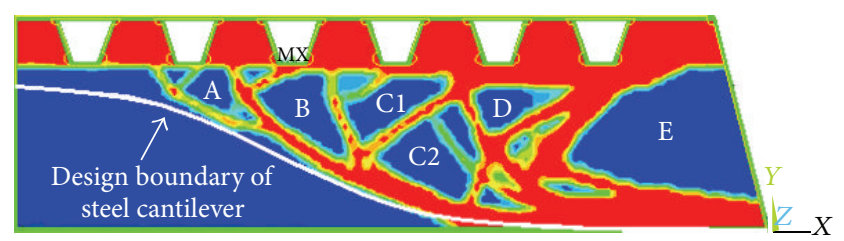

FIGURE 12: Topological optimization result for load weight coefficient $(0,1)$.

of steel cantilever. As to this minimum compliance design problem, the material distribution results for three kinds of weight coefficients (the weight coefficients of Load Case 1 and Load Case 2 are selected as $(1,0),(0.5,0.5)$, and $(0,1))$ are compared. Besides, the optimization results for different volume coefficients ( $20 \%$ to $60 \%$ ) are compared too. Based on the layout of them, the material distribution of $40 \%$ is selected for the more reasonable shape and hole parameters from the point of actual engineering. The optimization results for different kinds of weight coefficients when the volume coefficient is $40 \%$ are given in Figures 10 to 12 . As can be seen from them, on the premise of the same volume coefficient, the optimization results for different weight coefficients are similar, wherein blue area represents the area that does not need to arrange materials during structure design and red areas represent the areas that need to arrange materials. The 


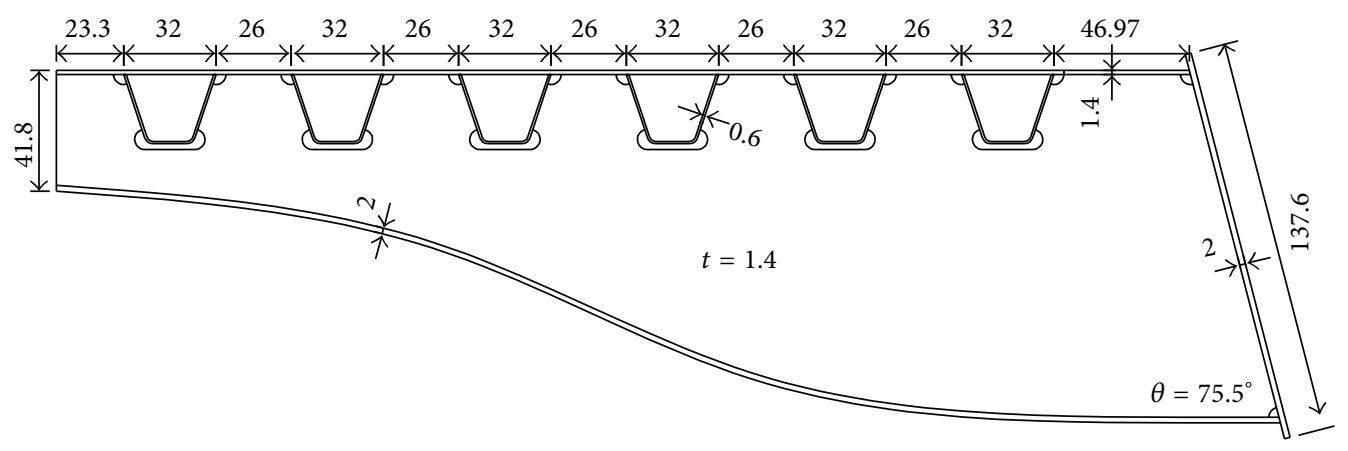

FIGURE 13: Steel cantilever optimization appearance design (unit: $\mathrm{cm}$ ).

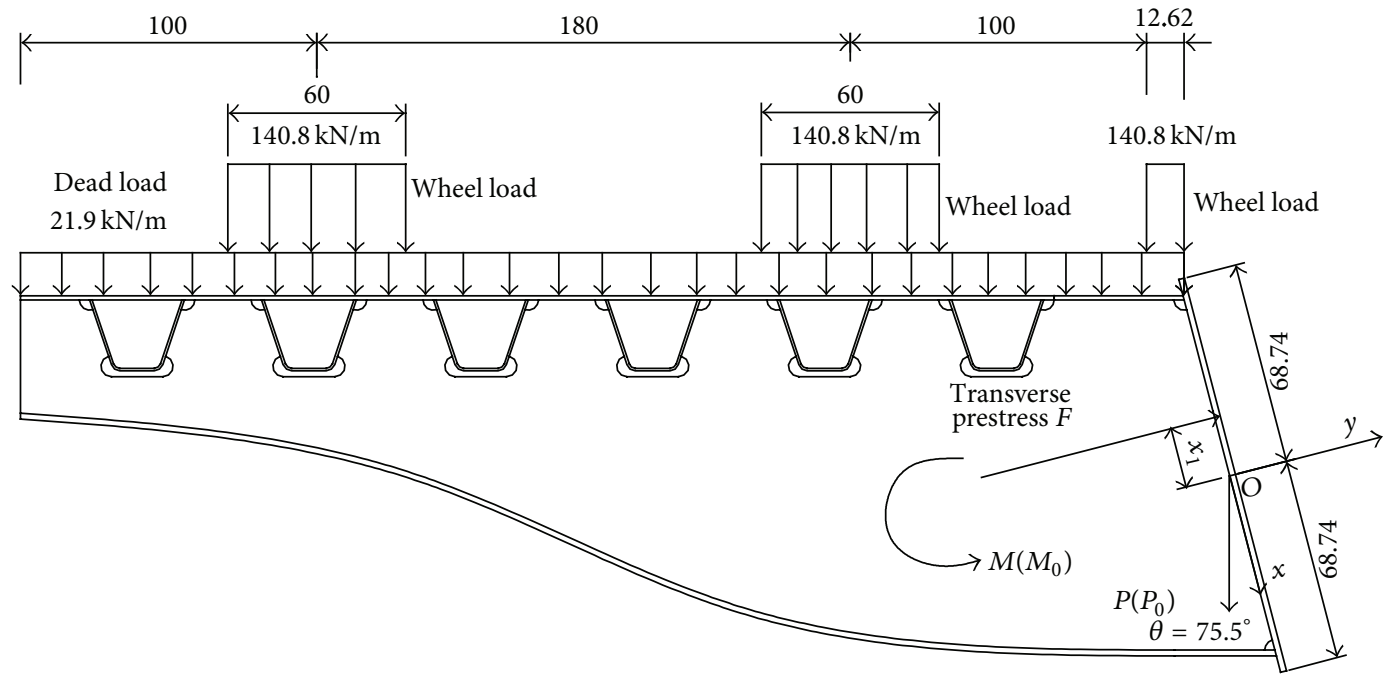

FIGURE 14: Steel cantilever mechanical model (unit: $\mathrm{cm}$ ).

results of topological optimization are used to confirm the boundary of steel cantilever and the positions of function holes. As it is shown in Figures 10 to 11, in the domain of the boundary of the steel cantilever, function holes which are used to settle pipelines should be placed in the blue area marked as A, B, C, and D. The area marked as E should not be punched because, under the transverse prestressed load, domain $\mathrm{E}$ is the key area of the prestress transmitting. But for this bridge, lighting at bridge deck is provided by street lamps on the ground and there are no other requirements for pipelines to pass by in early stage. Thus, functional holes are not needed to be set in steel cantilever beam. The streamlined boundary of steel cantilever is extracted as it is shown in Figure 13. In the future, the function holes can be set in the blue area marked as A, B, C, and D when they are needed.

6.3. Design for Load Position of Transverse Prestressed Tendons. Based on the shape and size of steel cantilevers that have been confirmed, under combined action of dead load, the most unfavorable live load and prestress, the mechanical model for steel cantilever beam is established as in Figure 14. The uniform load caused by bridge deck pavement is $21.9 \mathrm{kN} / \mathrm{m}$ and uniform force made by single wheel is $140.8 \mathrm{kN} / \mathrm{m}$, which is Critical Case II as illustrated in Section 4.1. The dead load on steel cantilever beam and wheel load are simplified as a concentrated force " $P$ " and bending moment " $M$ " that go through the bending center "O." The other critical case refers to the fact that only self-weight of steel cantilever beam and action of external prestressed tendons are considered during construction. Selfweight of steel cantilever beam is simplified as a concentrated force " $P_{0}$ " and bending moment " $M_{0}$ " that go through the bending center. The concrete strength grade of original girder is C30. In order to supply sufficient resistance to the steel cantilever beam, the concrete postpouring diaphragm needs enough compressive strength. So, C50 is selected for the postpouring diaphragm. During the derivation process, ultimate compressive strength of concrete $[\sigma]$ is valued as $22.4 \mathrm{MPa}$ according to the regulations for bridges /JTG D62$2004\rangle$. Specific values of other parameters under the two critical cases should be referred to in Table 1.

According to (23), the range of theoretical load position of transverse prestressed tendons in this example is calculated to be $0.19 \mathrm{~m}<x_{1}<0.32 \mathrm{~m}$. Within this range, the specific position of transverse prestressed tendons should be determined by considering these factors: when the transverse prestressed tendons go through the original girder, the damage to original girder should be minimized and the bending radius " $R$ " 
TABLE 1: Steel cantilever mechanics parameter.

\begin{tabular}{lccccccc}
\hline Load case & $M\left(M_{0}\right)(\mathrm{kNm})$ & $F(\mathrm{kN})$ & $P\left(P_{0}\right)(\mathrm{kN})$ & $\operatorname{Cos} \theta$ & {$[\sigma](\mathrm{MPa})$} & $l(\mathrm{~m})$ & $x_{1}(\mathrm{~m})$ \\
\hline Dead load + live load & 555.43 & 1430 & 252.92 & 0.25 & 22.4 & 1.226 & Lower limit 0.19 \\
\hline Self-weight & 181.95 & 1430 & 85.98 & 0.25 & 22.4 & 1.226 & Upper limit 0.32 \\
\hline
\end{tabular}

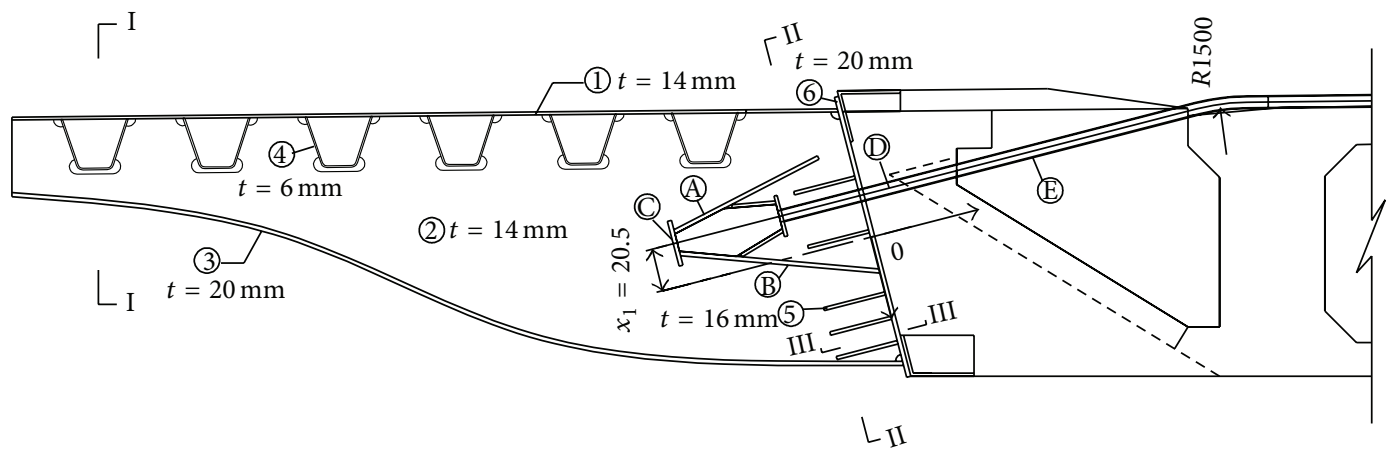

(1): roof, $14 \mathrm{~mm}$
(2): web, $14 \mathrm{~mm}$
(3): bottom flange plate, $20 \mathrm{~mm}$
(4): U-shaped rib, $6 \mathrm{~mm}$
(5): small stiffening rib, $16 \mathrm{~mm}$
(6): base plate, $20 \mathrm{~mm}$

FIGURE 15: Steel cantilever elevational drawing (unit: $\mathrm{mm}$ ). of transverse external prestressed tendons should meet the minimum specified value of epoxy coating steel strands.

Based on above factors and actual conditions of this girder, the position of transverse external prestressed tendons is determined as shown in Figure 15, wherein $x_{1}$ takes $20.5 \mathrm{~cm}$ and bending radius of transverse prestressed tendons is $R=$ $2 \mathrm{~m}$. The transverse prestress is $1430 \mathrm{kN}$, which could be offered by $10 \varphi 15.2 \mathrm{~mm}$ prestressed tendons, which are set symmetrically on both sides of steel cantilever slab as shown in Figure 17. The steel cantilevers at both sides of box girder are transversely combined with original box girder by 2 bundles (each bundles is composed by $5 \varphi 15.2 \mathrm{~mm}$ prestressed tendons) of external prestressed epoxy steel strands.

6.4. Detailed Design of Stiffening Rib. Stiffening rib of steel cantilever should be designed in detail on the basis of confirmed shape of steel cantilever and load position of transverse prestressed tendons. During the designing process, the reasonable stress on interface is an important reference index. In order to ensure that the steel cantilever and original girder are reliably combined, principles of the stress on the interface between steel cantilever beam and concrete postpouring diaphragm should be confirmed as follows: the key regions of concrete postpouring diaphragm interface which are under the base plate at web, roof, and bottom flange plate as shown in Figure 15 should keep in compression to avoid from being separated from steel cantilever and the maximum compressive stress of concrete interface should be ensured not to exceed local compressive admissible value of postpouring diaphragm concrete.
Under direction of the above principles, stiffening ribs of steel cantilever are designed in detail. In order to make the force at steel cantilever able to transmit to original girder uniformly, a steel base plate with thickness of $20 \mathrm{~mm}$ is placed at the interface between steel cantilever and concrete diaphragm and several stiffening ribs are set on the base plate. Setting stiffening ribs could also guarantee that the external force is transmitted to the interface effectively and evenly. Transverse prestressed tendons especially at both sides of web need to be anchored to Anchor Plate $\mathrm{C}$ that is vertical to the webs and the prestress is transferred to interface through Diagonal Rib A, Diagonal Rib B, and Web (2) as shown in Figure 15. Specific size of various components should be referred to in Figures 15 and 16. Structure of the actual bridge should be referred to in Figure 18.

6.5. Stress Analysis on Steel-Concrete Interface. After detailed design, the reasonability and feasibility of the whole optimal design should be verified by analyzing the stress on the steelconcrete interface.

According to above design parameters, finite element model is established and the girder with $3 \mathrm{~m}$ long is taken from the widened girder to analyze. In this paper, ANSYS FEA software is used to analyze the stress on the interface. SOLID 95 with 20 nodes is used to simulate original concrete box girder and postpouring concrete diaphragm. SHELL63 is used to simulate steel plate structures including steel cantilever beam, orthotropic bridge deck slab, stiffening rib, and steel base plate. Link 10 tension-only element is used to simulate prestressed tendons. Concrete element at the interface is divided into hexahedral mesh grids and the steel 


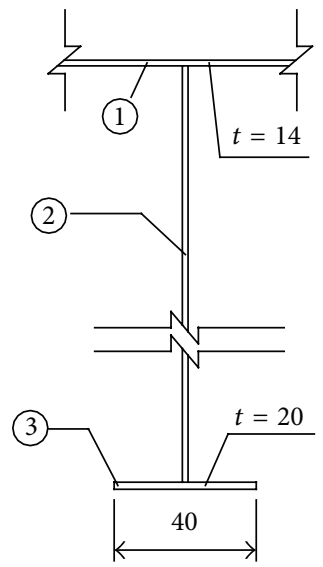

I-I cross section

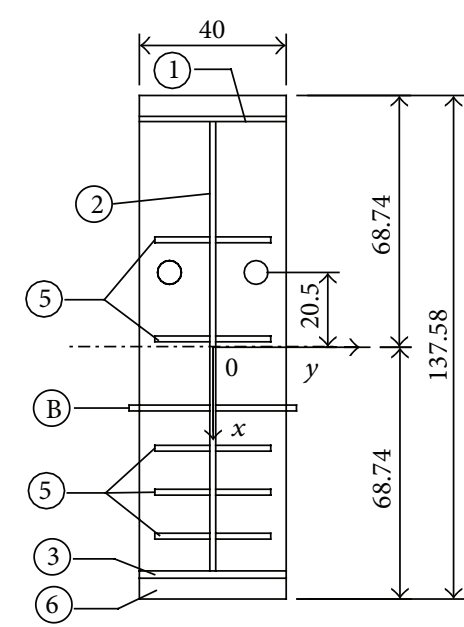

II-II cross section

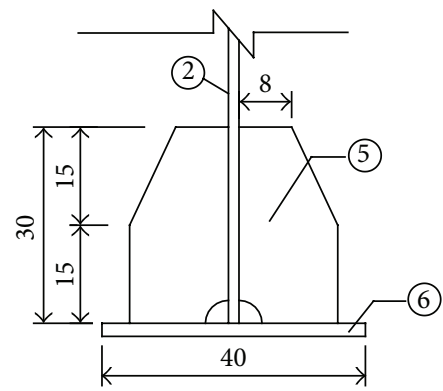

III-III cross section

FIGURE 16: Section schematic diagram (unit: $\mathrm{mm}$ ).

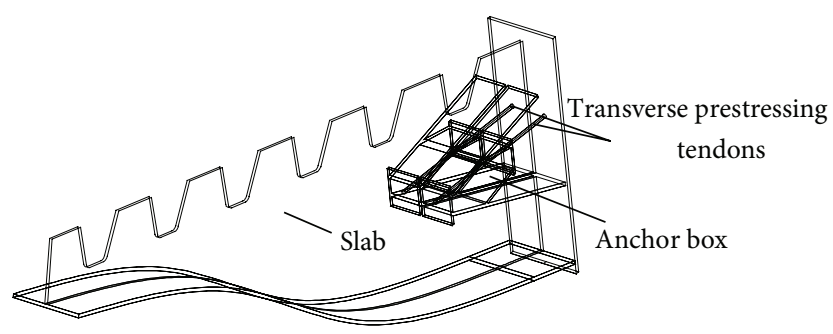

Figure 17: Details of the steel cantilever beam.
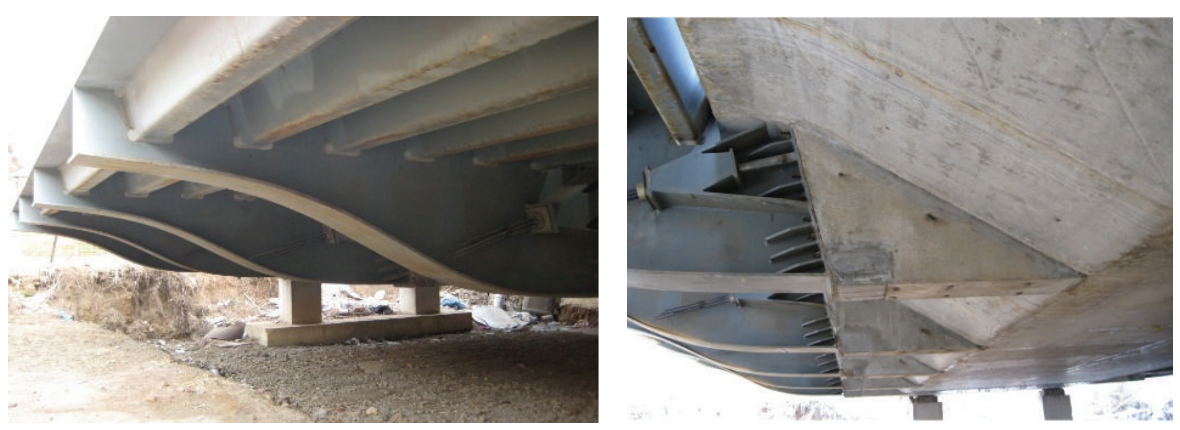

FIGURE 18: A case for optimization design of bridge.

base plate of steel cantilever is divided into the same mesh to ensure that the interface is connected truly and reliably. Link 10 compression-only element is used to connect the steel base plate and the concrete, which can simulate axial force in the direction of $y$, while the contact conditions in other directions are simulated by the coupled equations. Finite element model is shown in Figures 19 and 20.

Local stress analysis on widened bridge structure is loaded by $20 t$ vehicle with $70 \mathrm{kN}$ front shaft and $130 \mathrm{kN}$ back shaft. The most unfavorable condition is the case when the back shaft is loaded on the cantilever. According to the regulations of bridges 〈JTG D62-2004〉, impact effect should be included here and impact coefficient should take 1.3. Thus, the load of back shaft should be exerted as $1.3 \times 130 \mathrm{kN}=$ $169 \mathrm{kN}$.

Two critical cases are adopted as follows.

Critical Case I is in the construction state. In this stage the self-weight and prestress are considered. The objective of Case I is checking if compressive stress on top of the interface exceeds allowable value of C50 and if the bottom of the interface open when prestressed tendon is stretched.

Critical Case II is in the service status. Self-weight, dead load, prestress, and live load of four lanes are considered in this stage. The objective is checking if top of the interface 


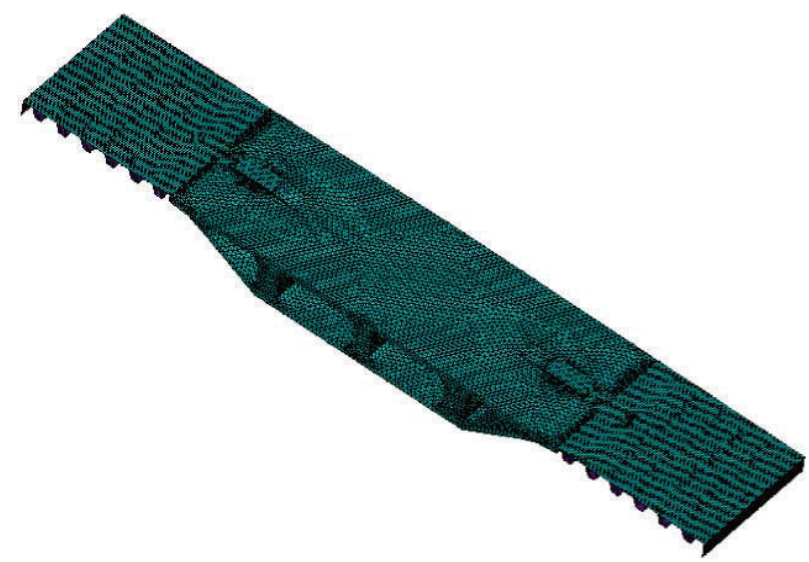

FIGURE 19: Finite element model.
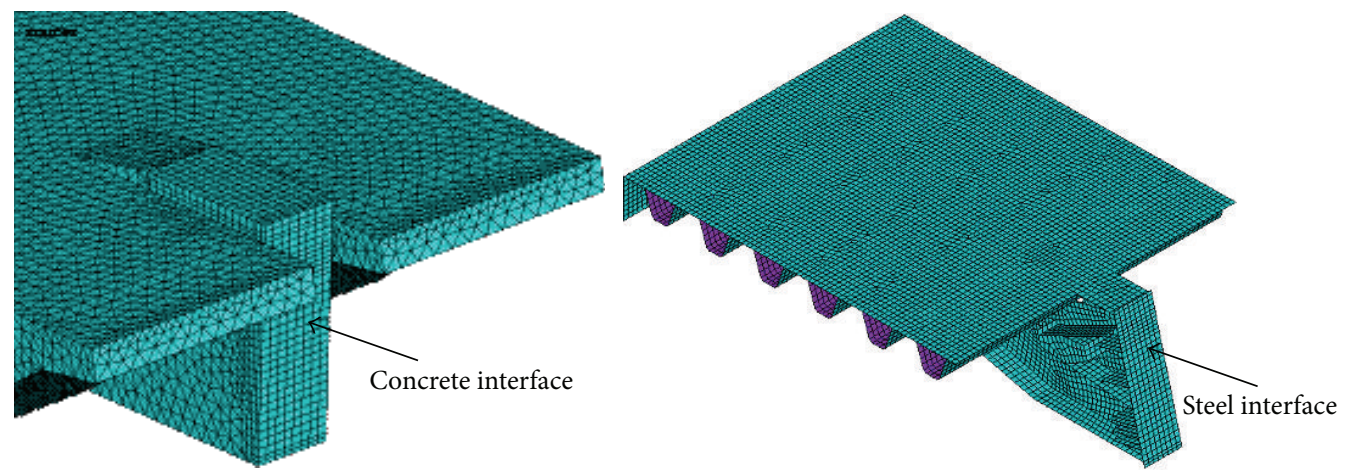

Figure 20: Finite element model of interface.

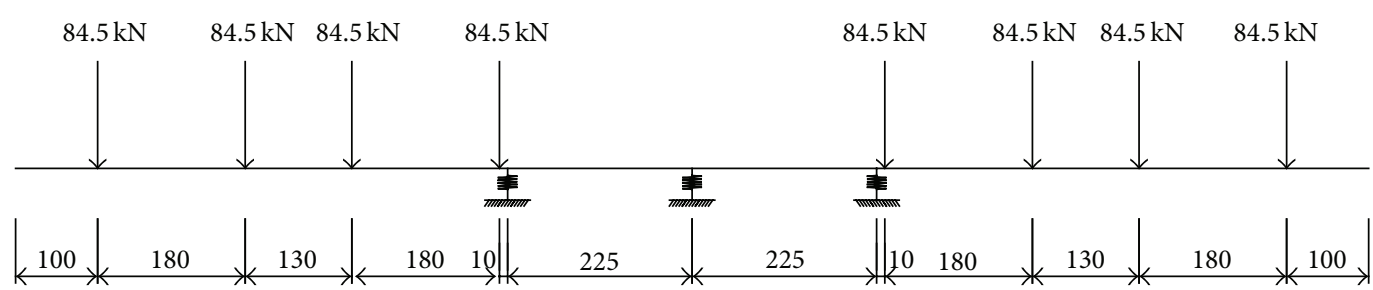

FIgURE 21: Load spread schematic diagram of model two.

between concrete and steel beam opens and if the compressive stress on the bottom exceeds admissible value of C50. Load arrangement should be referred to in Figure 21.

Stress on the interface for Case I is shown in Figure 22. It could be concluded from this figure that the key regions of interface at web, roof, and bottom flange is under compression. Local maximum compressive stress of concrete interface is $14.4 \mathrm{MPa}$ and this value is smaller than compressive strength of C50 concrete used for postpouring diaphragm as 22.4 MPa. And from enlarged stress nephogram for normal stress at bottom edge of the interface, it could be concluded that tensile stress does not happen to bottom edge of interface under this case.

Stress on interface for Case II should be referred to in Figure 23. It could be concluded that the key regions of the interface is also under compression. Local maximum compressive stress for concrete is $16.9 \mathrm{MPa}$, which is smaller than compressive stress of concrete postpouring diaphragm, so as to ensure that the concrete at interface is safely compressed. In this case, the top of the interface is easy to open, while the enlarged cloud diagram for the stress at top edge shows that this position is under compression too.

Thus, it could be concluded that, under both of the two critical cases, the interface between steel cantilever beam and concrete postpouring diaphragm is ensured to be closed and the concrete at interface is ensured not to be crushed. The stress results show the interface is reasonably compressed, which meets the design requirements.

\section{Conclusions}

The structural optimization method of steel cantilever used in concrete box girder bridge widening is illustrated in this paper, which is a new box girder widening method with 

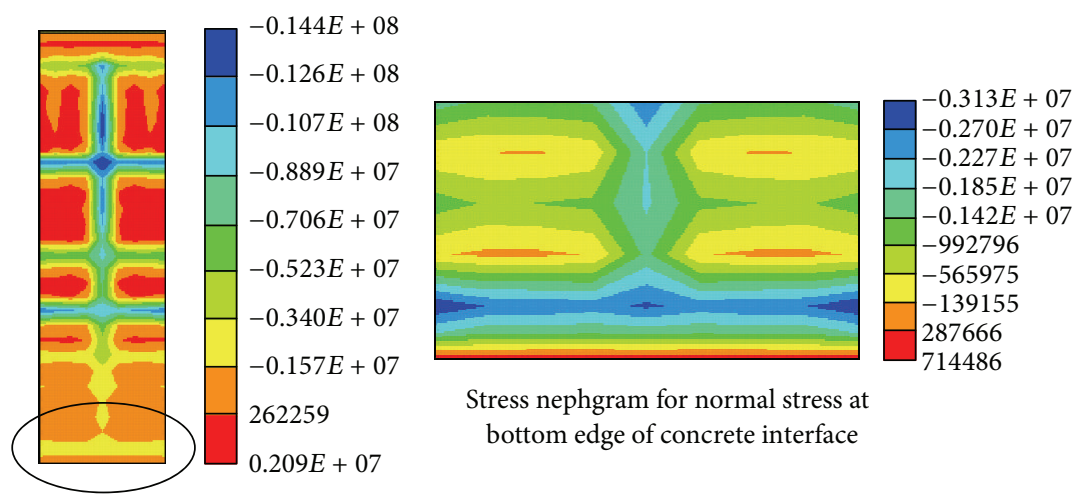

Stress nephgram for normal stress at

bottom edge of concrete interface

Stress nephgram for normal stress of concrete interface

FIGURE 22: Concrete interface normal stress diagram of Case I.
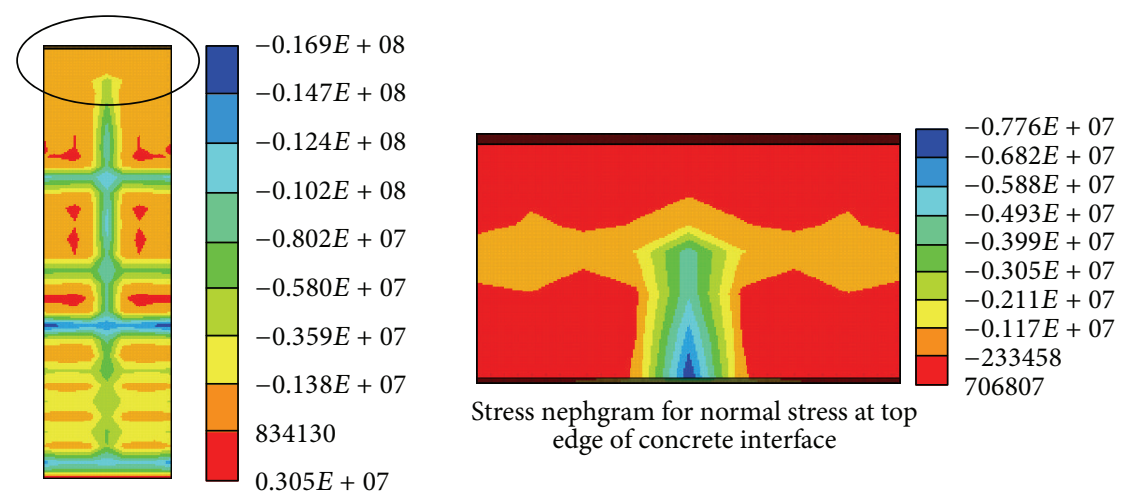

Stress nephgram for normal stress of concrete interface

FIgURE 23: Concrete interface normal stress diagram of Case II.

various advantages. In order to promote actual application of this method, relevant researches on the structural optimization of steel cantilever are made and the following could be concluded.

(1) The authors have introduced the topological optimization theory to get reasonable material distribution results within design area for steel cantilever. And this topological result provides theoretical basis for the determination of shape and arrangement of function holes of steel cantilever beam.

(2) Authors have made stress analysis on the interface between steel cantilever and concrete postpouring diaphragm. In order to prevent tensile stress from happening to the interface under any load cases and make compressive stress not to exceed admissible value for compressive strength of the postpouring diaphragm, basic mechanical model for steel cantilever beam under two critical load cases has been established and the analytical expression of the optimal action range of transverse prestressed tendons has been deduced according to plane cross-section assumption.

(3) In this paper, an optimization design scheme based on the stress at steel-concrete interface has been given, which is applied to a real bridge. The analysis results indicate that using this optimization design scheme to make optimization design on steel cantilever could get the scheme that meets design requirements with reasonable stress. This method could reduce unnecessary trials and save computing resource to the greatest extent, so as to realize rapid and accurate design.

This structural optimization method provides the theoretical support to the promotion of steel cantilever widening concrete box girder method and also promotes the application of structural optimization theory in bridge design.

\section{Conflict of Interests}

The authors declare that there is no conflict of interests regarding the publication of this paper. 


\section{Acknowledgments}

The research described in this paper was financially supported by the science and technology funds of Liaoning Education Department (20131021) and the National Natural Science Foundation of China (51308090).

\section{References}

[1] S. Allahdadian and B. Boroomand, "Design and retrofitting of structures under transient dynamic loads by a topology optimization scheme," in Proceedings of the 3rd International Conference on Seismic Retrofitting, pp. 1-9, Iranian NorthWest Retrofitting Center, Iranian Retrofitting Researchers Institute, Tabriz, Iran, October 2010.

[2] L. Stromberg, A. Beghini, W. F. Baker, and G. H. Paulino, "Design of structural braced frames using group optimization," in Proceedings of the 20th Analysis and Computation Specialty Conference, vol. 10, pp. 267-277, 2012.

[3] L. L. Beghini, A. Beghini, N. Katz, W. F. Baker, and G. H. Paulino, "Connecting architecture and engineering through structural topology optimization," Engineering Structures, vol. 59, pp. 716-726, 2014.

[4] J. K. Guest, R. Lotfi, A. T. Gaynor, and M. Jalalpour, "Structural topology optimization: moving beyond linear elastic design objectives," in Proceedings of the 20th Analysis and Computation Specialty Conference, pp. 245-256, Chicago, Ill, USA, March 2012.

[5] L. L. Stromberg, A. Beghini, W. F. Baker, and G. H. Paulino, "Application of layout and topology optimization using pattern gradation for the conceptual design of buildings," Structural and Multidisciplinary Optimization, vol. 43, no. 2, pp. 165-180, 2011.

[6] B. Briseghella, L. Fenu, C. Lan, E. Mazzarolo, and T. Zordan, "Application of topological optimization to bridge design," Journal of Bridge Engineering, vol. 18, no. 8, pp. 790-800, 2013.

[7] H. Guan, Y.-J. Chen, Y.-C. Loo, Y.-M. Xie, and G. P. Steven, "Bridge topology optimisation with stress, displacement and frequency constraints," Computers \& Structures, vol. 81, no. 3, pp. 131-145, 2003.

[8] E. Fauche, S. Adriaenssens, and J. H. Prevost, "Structural optimization of a thin-shell bridge structure," Journal of the International Association for Shell and Spatial Structures, vol. 51, no. 2, p. 153, 2010.

[9] V. Goremikins, K. Rocens, and D. Serdjuks, "Topology optimization of cable Truss web for prestressed suspension bridge," World Academy of Science, Engineering and Technology, vol. 73, pp. 41-47, 2013.

[10] M. Daifuku, T. Nishizu, A. Takezawa, M. Kitamura, H. Terashita, and Y. Ohtsuki, "Design methodology using topology optimization for anti-vibration reinforcement of generators in a ship's engine room," Proceedings of the Institution of Mechanical Engineers Part M: Journal of Engineering for the Maritime Environment, 2014.

[11] M. Bruggi, "Generating strut-and-tie patterns for reinforced concrete structures using topology optimization," Computers \& Structures, vol. 87, no. 23-24, pp. 1483-1495, 2009.

[12] M. Victoria, O. M. Querin, and P. Marti, "Generation of strutand-tie models by topology design using different material properties in tension and compression," Structural and Multidisciplinary Optimization, vol. 44, no. 2, pp. 247-258, 2011.
[13] Y. Yang, C. D. Moen, and J. K. Guest, “Three-dimensional force flow paths and reinforcement design in concrete via stressdependent truss-continuum topology optimization," Journal of Engineering Mechanics, vol. 141, no. 1, Article ID 04014106, 2014.

[14] M. Bruggi and A. Taliercio, "Topology optimization of the fiberreinforcement retrofitting existing structures," International Journal of Solids and Structures, vol. 50, no. 1, pp. 121-136, 2013.

[15] M. Bruggi, G. Milani, and A. Taliercio, "Design of the optimal fiber-reinforcement for masonry structures via topology optimization," International Journal of Solids and Structures, vol. 50, no. 13, pp. 2087-2106, 2013.

[16] M. Bruggi, G. Milani, and A. Taliercio, "Simple topology optimization strategy for the FRP reinforcement of masonry walls in two-way bending," Computers and Structures, vol. 138, no. 1, pp. 86-101, 2014.

[17] Q. Wang and Z. Zhang, "Orthotropic steel cantilever widening method of concrete box girder," Structural Engineering International, vol. 21, no. 2, pp. 228-232, 2011.

[18] Q. Wang, L. Shi, and Z. Zhang, "Application of a new kind of widening method in Dalian Northeast Road overpass improvement project," in Proceedings of the 9th International Conference on Civil and Environmental Engineering, Dalian, China, November 2010.

[19] M. Majowiecki, "The free form design (FFD) in steel structural architecture-aesthetic values and reliability," Steel Construction, vol. 1, no. 1, pp. 3-15, 2008.

[20] M. Majowiecki, "Ethics and structural reliability in free-form design (FFD)," Journal of the International Association for Shell and Spatial Structures, vol. 48, no. 4, pp. 29-50, 2007.

[21] M. P. Bendsøe and N. Kikuchi, "Generating optimal topologies in structural design using a homogenization method," Computer Methods in Applied Mechanics and Engineering, vol. 71, no. 2, pp. 197-224, 1988.

[22] M. P. Bendsøe, Optimization of Structural Topology, Shape, and Material, Springer, Berlin, Germany, 1995.

[23] M. P. Bendsøe and O. Sigmund, Topology Optimization: Theory, Methods, and Applications, Springer, Berlin, Germany, 2003.

[24] H. P. Mlejnek and R. Schirrmacher, "An engineer's approach to optimal material distribution and shape finding," Computer Methods in Applied Mechanics and Engineering, vol. 106, no. 1-2, pp. 1-26, 1993.

[25] Y. M. Xie and G. P. Steven, "A simple evolutionary procedure for structural optimization," Computers and Structures, vol. 49, no. 5, pp. 885-896, 1993.

[26] Y. M. Xie and G. P. Steven, Evolutionary Structural Optimization, Springer, Berlin, Germany, 1997.

[27] X. Y. Yang, Y. M. Xie, G. P. Steven, and O. M. Querin, "Bidirectional evolutionary method for stiffness optimization," AIAA Journal, vol. 37, no. 11, pp. 1483-1488, 1999.

[28] O. M. Querin, V. Young, G. P. Steven, and Y. M. Xie, “Computational efficiency and validation of bi-directional evolutionary structural optimization," Computer Methods in Applied Mechanics and Engineering, vol. 189, no. 2, pp. 559-573, 2000.

[29] X. Huang and Y. M. Xie, "Topology optimization of nonlinear structures under displacement loading," Engineering Structures, vol. 30, no. 7, pp. 2057-2068, 2008.

[30] M. P. Bendsøe, "Optimal shape design as a material distribution problem," Structural Optimization, vol. 1, no. 4, pp. 193-202, 1989.

[31] M. P. Bendsøe and O. Sigmund, "Material interpolation schemes in topology optimization," Archive of Applied Mechanics, vol. 69, no. 9-10, pp. 635-654, 1999. 
[32] G. I. N. Rozvany, "Aims, scope, methods, history and unified terminology of computer-aided topology optimization in structural mechanics," Structural and Multidisciplinary Optimization, vol. 21, no. 2, pp. 90-108, 2001.

[33] X. Zhou, L. Chen, and Z. Huang, "The SIMP-SRV method for stiffness topology optimization of continuum structures," International Journal of CAD/CAM, vol. 7, no. 1, 2009.

[34] Ministry of Transport of the People's Republic of China (MOT), Code for Design of Highway Reinforced Concrete and Prestressed Concrete Bridges and Culverts, JTG D62-2004, Ministry of Transport of the People's Republic of China (MOT), Beijing, China, 2004.

[35] O. Sigmund, "A 99 line topology optimization code written in Matlab," Structural and Multidisciplinary Optimization, vol. 21, no. 2, pp. 120-127, 2001.

[36] M. P. Bendsøe and O. Sigmund, Topology Optimization, Theory, Methods, and Applications, Springer, Berlin, Germany, 2004.

[37] M. Bruggi, "On the automatic generation of strut and tie patterns under multiple load cases with application to the aseismic design of concrete structures," Advances in Structural Engineering, vol. 13, no. 6, pp. 1167-1181, 2010. 


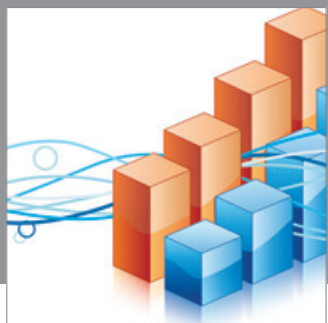

Advances in

Operations Research

mansans

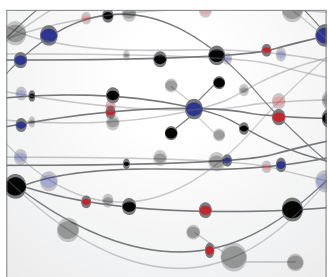

The Scientific World Journal
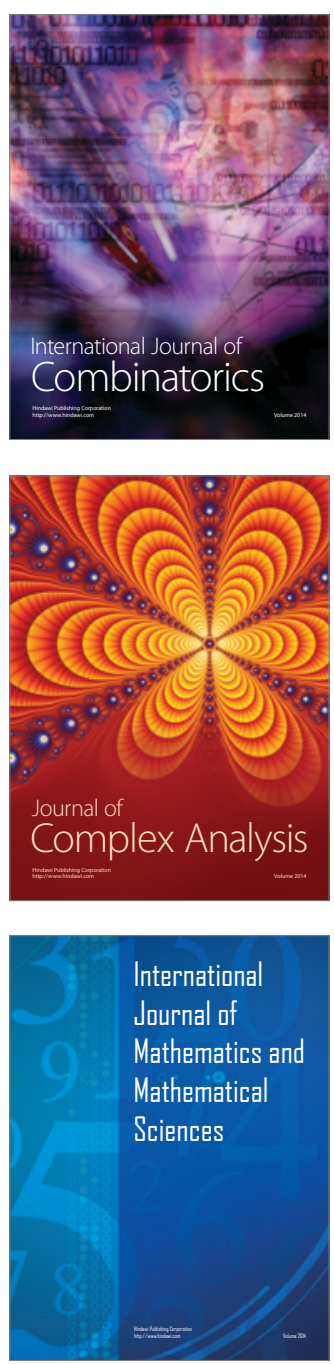
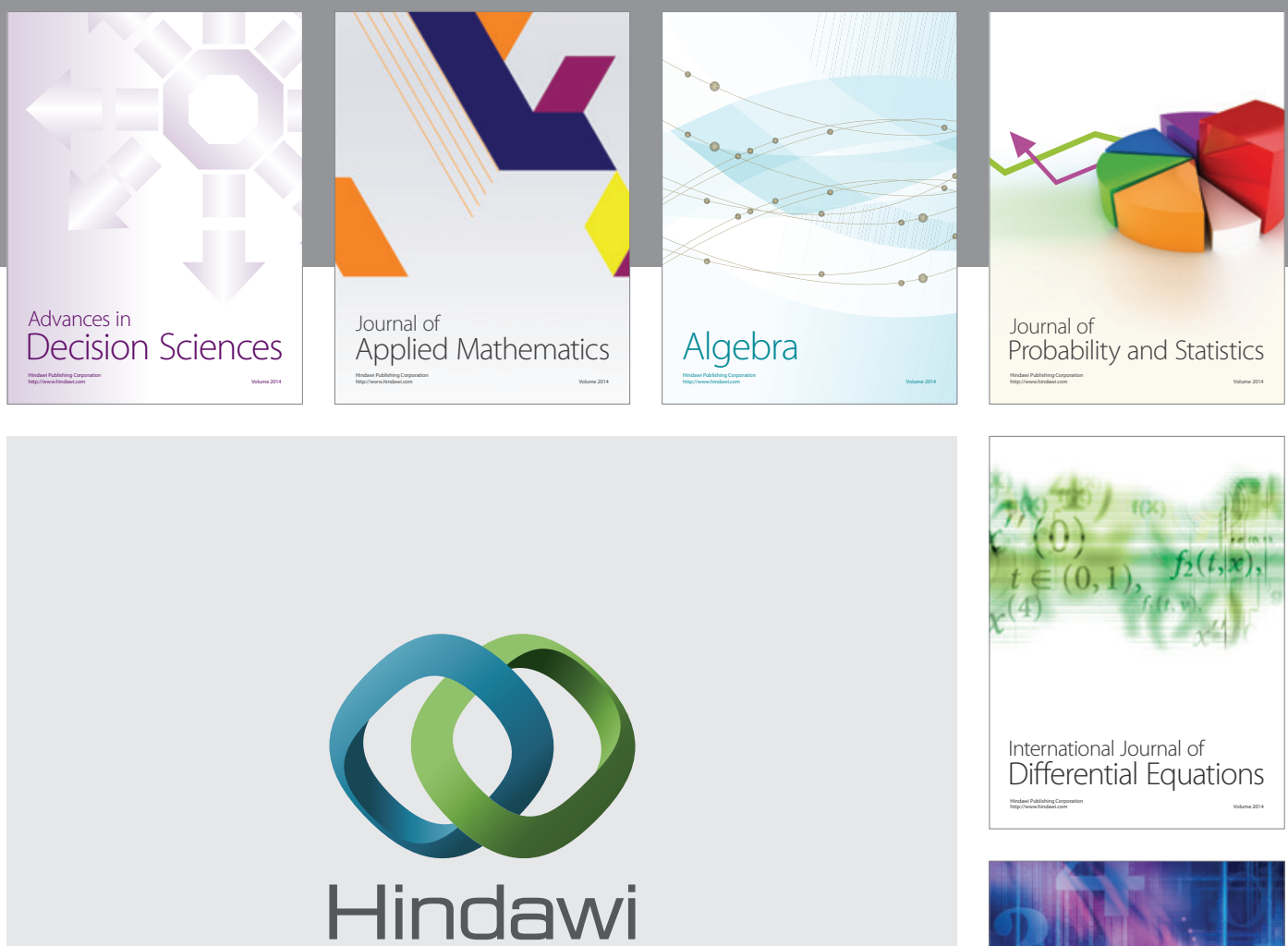

Submit your manuscripts at http://www.hindawi.com
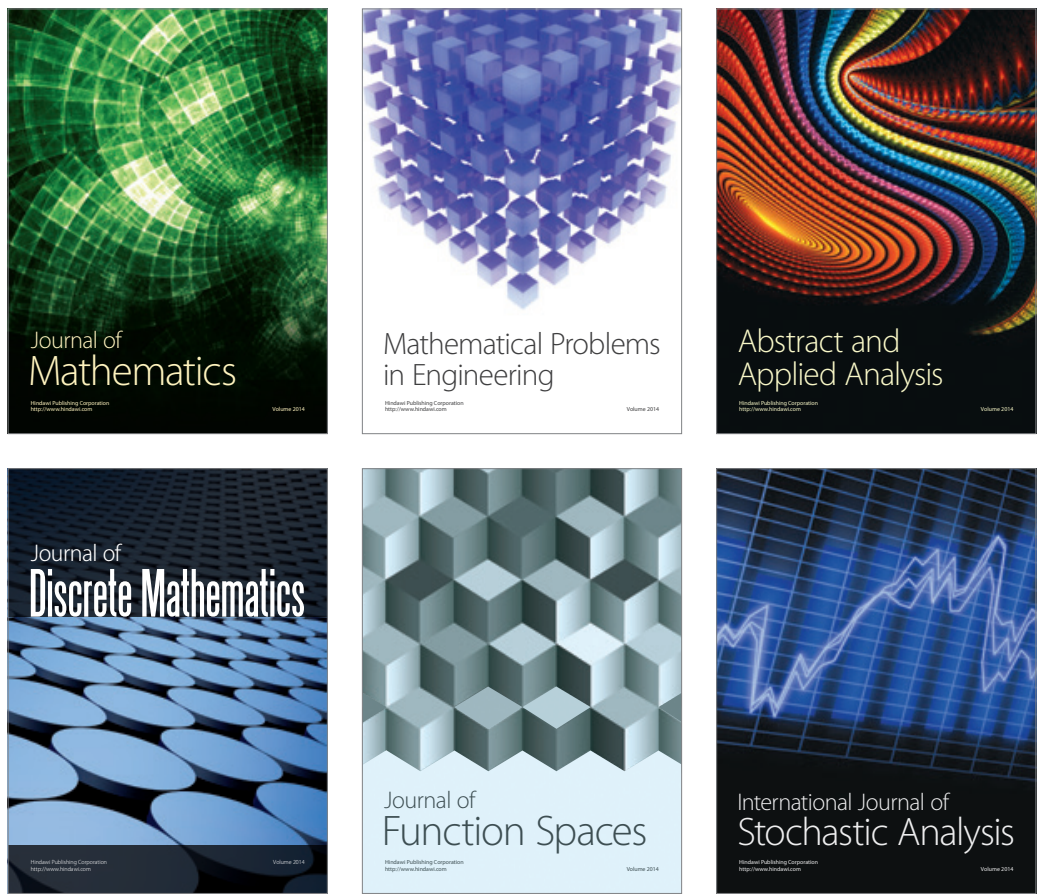

Journal of

Function Spaces

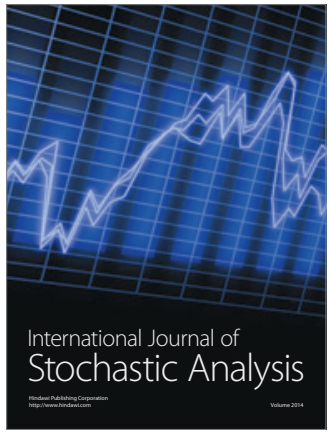

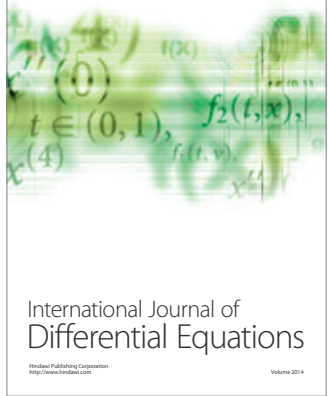
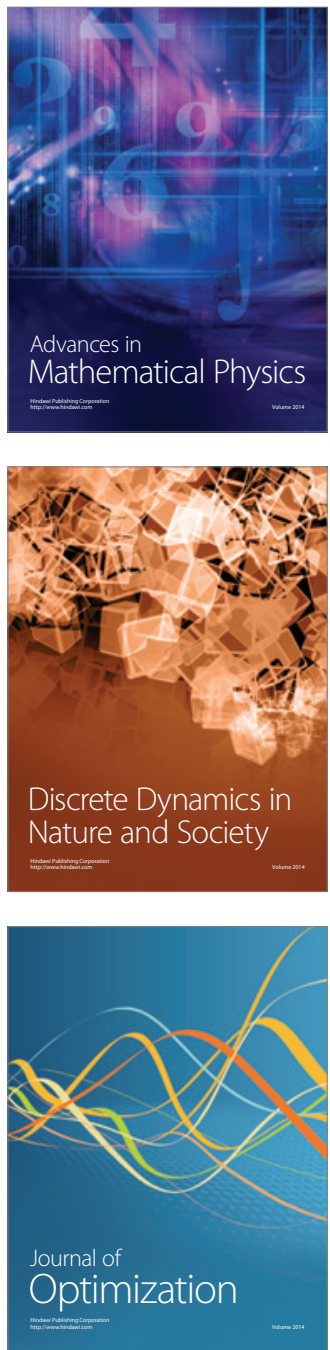